\title{
A Comparative Life Cycle Assessment of Different Production Processes for Waterborne Polyurethane Dispersions
}

\author{
Valentin Klug, ${ }^{\dagger}, \S$ Josef-Peter Schöggl, $\$$ Doris Dallinger, ${ }^{\dagger}, \neq$ Clemens Stueckler, ${ }^{\#}$ Andreas Steiner, ${ }^{\#}$ Anton Arzt, ${ }^{\#}$ C. \\ Oliver Kappe, ${ }^{*},{ }^{,}, *$ and Rupert J. Baumgartner, ${ }^{*}, S$ \\ † Institute of Chemistry, University of Graz, NAWI Graz, Heinrichstrasse 28, 8010 Graz, Austria \\ $\S$ Christian Doppler Laboratory for Sustainable Product Management, Institute of Systems Sciences, Innovation and \\ Sustainability Research, University of Graz, Merangasse 18/I, 8010 Graz, Austria \\ $\ddagger$ Center for Continuous Flow Synthesis and Processing (CCFLOW), Research Center Pharmaceutical Engineering \\ GmbH (RCPE), Inffeldgasse 13, 8010 Graz, Austria
}

\# Allnex Austria GmbH, Bundesstrasse 175, 8402 Werndorf, Austria

KEYWORDS: Life cycle assessment, Polyurethane dispersions, Waterborne polyurethanes, Continuous flow, Cradleto-gate

\begin{abstract}
Waterborne polyurethane dispersions have gained significant importance in the coating industry due to their diverse chemical and physical properties. However, a comprehensive analysis of their environmental impacts is lacking. Therefore, this study provides a comparative life cycle assessment (LCA) of four different polyurethane dispersion production processes from cradle-to-gate. The environmental performances of the NMP process, the acetone process, the melt process, and a conceptualized continuous flow process were evaluated and compared following the CML 2001 methodology. The LCA revealed that the conceptualized flow process exhibits the lowest environmental impact in all investigated impact categories. Depending on the impact category, the melt process or the acetone process rank second. The NMP process was observed to have the highest impact in all categories. Consequently, the flow process has the lowest carbon footprint $(1,13$ $\mathrm{kg} \mathrm{CO}$-eq), according to the global warming potential (10o years), followed by the melt (1,45 $\mathrm{kg} \mathrm{CO}_{2}$-eq), the acetone $(1,95$ $\mathrm{kg} \mathrm{CO}$-eq) and the NMP process $\left(3,11 \mathrm{~kg} \mathrm{CO}_{2}\right.$-eq).
\end{abstract}

\section{INTRODUCTION}

Polyurethanes (PUs) are undoubtedly one of the most versatile plastic materials, as they can be designed in order to fulfil different material requirements. ${ }^{1-4}$ Because of their diverse properties they find broad applications as flexible and rigid foams, coatings, adhesives and sealants, elastomers, paints or in medical devices. PUs are widely employed in various industries such as furniture, construction, electronics, automotive, footwear or packaging and hold a market size of ca. $5 \%$ of the total world consumption of plastics (PUs being the fifth largest polymer in overall volume) ${ }^{3}$

In the past decades, a replacement for solvent-borne PU systems was urgently required as a result of the implementation of more stringent environmental and occupational health regulations. Therefore, waterborne polyurethane dispersions (PUDs) have gained a great significance in the field of PU technology, as they meet the regulatory compliance toward low level emissions of volatile organic compounds (VOCs). ${ }^{5}$ Importantly, the flexibility of the production process allows the molecular weight of waterborne PUDs - and as a result also the performance of the polymers - to be adjusted. They showcase excellent abrasion and chemical resistance, adhesion to various substrates and possess a unique combination of toughness and flexibility. ${ }^{1-3}$ Due to these properties they are of particular interest for coating applications in the automotive, textile, leather, metal and plastics industries or as wood and concrete architectural coatings. ${ }^{1}$

The manufacture of waterborne PUDs generally comprises three steps: a) synthesis of an isocyanate (NCO)terminated prepolymer from diisocyanates and longchained polyols, b) dispersion of the prepolymer in water, and c) chain extension (Scheme 1). Commercially most predominant are anionic PUDs. Here, a stabilizer/modifier usually dimethylol propionic acid (DMPA) - is added to the diisocyanate/polyol mix during the prepolymer generation. The prepolymer is then dispersed in water with a suitable neutralizing agent such as triethylamine $\left(\mathrm{Et}_{3} \mathrm{~N}\right)$, which reacts with the carboxylic acid generating a watersoluble salt. Finally, chain extension by reaction of the terminal NCO moieties with a polyamine furnishes the final molecular weight of the polymer. Within the finished product, the average solid content of PUDs is between 30 and $50 \%{ }^{1}$ 
The most-widespread methods for the production of waterborne PUDs are the NMP, acetone or melt processes. ${ }^{1}$ Whereas an organic solvent is employed in the NMP and acetone process in the prepolymer formation phase for viscosity reasons, the melt process is organic solvent-free, which makes it the most environment-friendly process. Nevertheless, acetone - as low-boiling solvent - can be distilled and recycled. It is therefore removed from the final product, but NMP ( $N$-methyl-2-pyrrolidone) - as highboiling solvent - remains. Because of its hazardous properties, ${ }^{6}$ the use of NMP has been restricted by the European Commission in April 2018, ${ }^{7}$ thus consequently enforcing NMP-free manufacturing variants. ${ }^{8}$

A very promising alternative would be the application of the melt process in a continuous flow production format ("continuous manufacturing"), which has not yet been reported for PUD production to the best of our knowledge. Due to the process intensification potential of continuous flow, $9^{-11}$ the prepolymer formation could be conducted at a higher temperature, thereby enhancing the reaction rate. Other advantages, such as precise residence time control, reproducibility, better product quality, safety, easy scalability and small inventory are compelling reasons for the implementation of continuous flow reactors. Most importantly, continuous manufacturing also contributes toward greener and more sustainable processes. ${ }^{12-16}$

Despite the growing environmental concerns, no study has assessed and compared the environmental impacts related to the production of PUDs so far. Previous research at the junction of PU chemistry and sustainability aspects

\section{Scheme 1. Synthesis of Anionic Waterborne PUDs.}

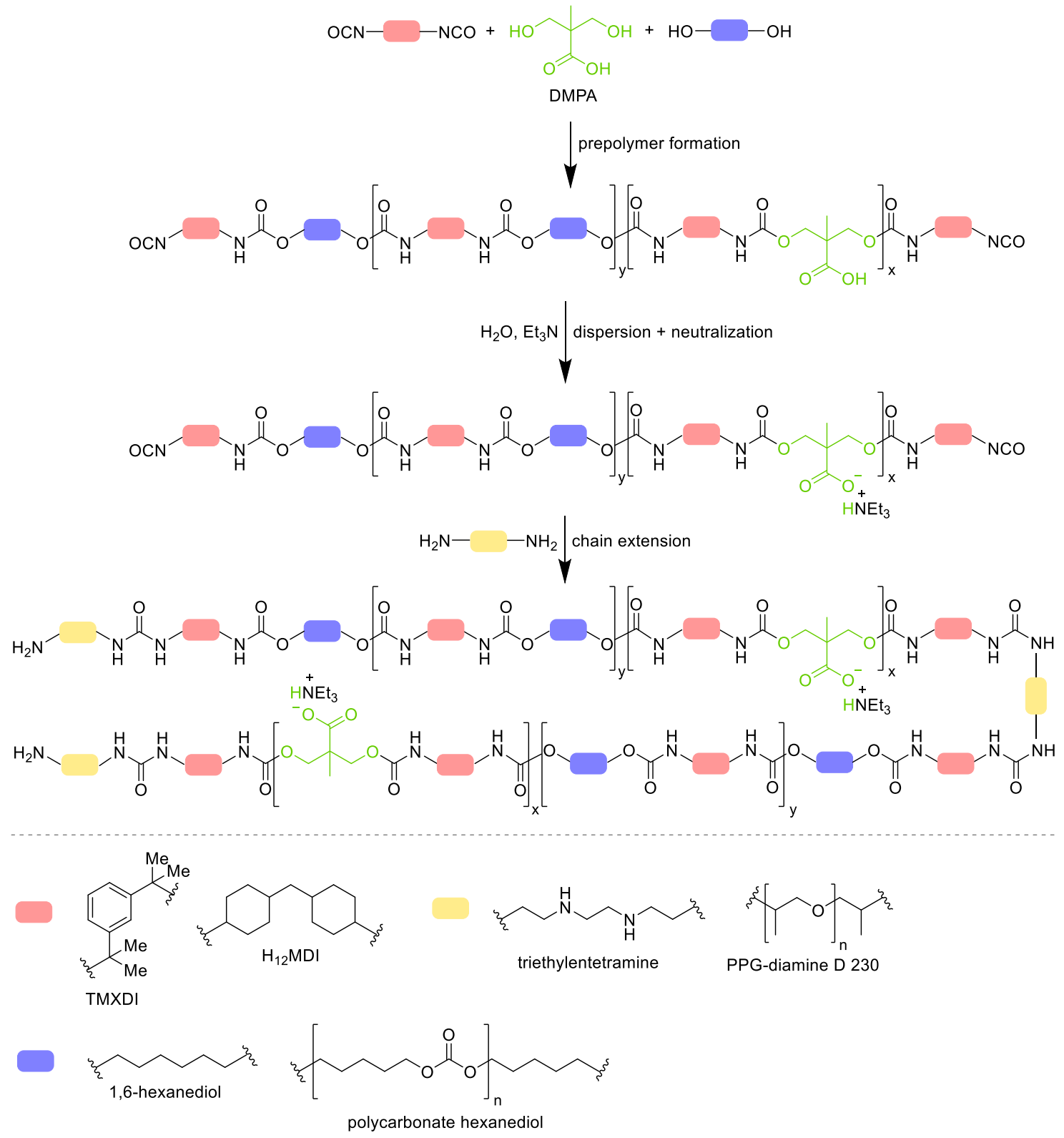


mainly focused on improving the adhesive's physical and chemical parameters, ${ }^{17-21}$ and none of these studies conducted a full life cycle assessment (LCA). Herein, we present a comparative LCA of the following four PUD production processes: (1) NMP process, (2) acetone process, (3) melt process, and (4) a continuous flow process. In this context it is important to outline that products with an identical technical performance in the desired end-application were chosen for this comparison. Therefore, the raw materials needed to be adapted to the respective PUD process.

Data on the first three established processes were provided by Allnex Austria GmbH, a PUD producer in Austria. Data for the continuous flow process, on the other hand, were in part modeled as this process is currently in the design stage. The major driver for this study was to evaluate if a continuous flow process would result in a more sustainable PUD production.

\section{METHODOLOGY}

The comparative LCA followed the ISO 14040/44 LCA framework. ${ }^{22}$ The relevant material and energy flows of each of the four different processes were modeled using the Umberto LCA+ software. One kilogram of finished product acted as the functional unit to which all mass and energy flows of the four PUD production processes were referred to.

The study followed a cradle-to-gate approach and, thus, accounts for impacts that occur from the acquisition of raw materials to the end of the manufacturing process. Additional impacts caused during the remainder of the finished PUD's lifetime were not considered. The material and energy required for the construction and provision of the technical equipment, such as the reactors utilized, were also excluded. The following six CML 2001 baseline indicators were used in the impact assessment: global warming ( $\mathrm{kg} \mathrm{CO}_{2}$-eq), acidification ( $\mathrm{kg} \mathrm{SO}_{2}$-eq), eutrophication ( $\mathrm{kg} \mathrm{NO}_{\mathrm{x}}$-eq), human toxicity ( $\mathrm{kg} \mathrm{1,4-DCB-eq),} \mathrm{pho-}$ tochemical oxidation $\left(\mathrm{kg} \mathrm{C}_{2} \mathrm{H}_{4}\right.$-eq), and resource depletion (kg Sb-eq). The geographical area, as well as the technological system were defined as follows: The production took place in a PUD plant in Austria. Apart from emissions discharged into and raw materials being extracted from the environment, no further complex exchanges or interactions were modeled.

The operation time for one complete cycle, and therefore also for $1 \mathrm{~kg}$ of end product, differed for each of the processes. While the conceptualized flow process was laid out to have a very short duration of less than $1 \mathrm{~h}$, the acetone process needs more than $18 \mathrm{~h}$ for completion. However, the total time needed to finish a production cycle played a subordinate role in the case at hand. More important than the overall time needed to finish a cycle was the observation of the duration and intensity of energy consumption throughout the process. Primary data for the ground system was collected from Allnex Austria GmbH.
Secondary data for the background system was obtained from the ecoinvent database (version 3.5 and 3.6). ${ }^{23,24}$

\section{RESULTS AND DISCUSSION}

Life Cycle Inventory (LCI) Analysis. The LCI data for the four PUD production processes were compiled from their input chemicals and their energy dataset.

Process Inputs. Table 1 gives an overview of the input chemicals used for the PUD syntheses, which was provided from the PUD producer. Regarding the availability of LCI data of the utilized chemicals, three groups were differentiated: (1) Chemicals with adequately detailed LCI data available in ecoinvent, (2) chemicals that were required to be modeled from very similar compounds with existing relevant information, and (3) chemicals with neither sufficient LCI data nor suitable compounds acting as possible substitutes, requiring the input of the corresponding ecoinvent-known starting materials from their production processes according to literature. ${ }^{25}$

As illustrated in Table 1, NMP, deionized water, acetone and triethyl amine $\left(\mathrm{Et}_{3} \mathrm{~N}\right)$ were modeled based on ecoinvent 3.5 and 3.6 datasets with aggregated impacts. Chemicals lacking exact matches in the ecoinvent database were modeled upon appropriate substitutes for which relevant information was available in ecoinvent. Even though some finalizing chemical transformations and energy flows may differ between the substitutes and the original compound, e.g. due to variations of the synthesis process conduct or slightly different raw material concentrations, this method represented the best approximation, as the comprehensiveness and degree of precision of the ecoinvent data could not have been replicated. Thus, as shown in the second group in Table 1, for 1,6-hexanediol, DMPA, TMXDI, and triethylenetetramine the most appropriate substitutes were used. Chemicals that belong to the third group were modeled by using stoichiometric equations from published literature. The corresponding substrates were then characterized based on ecoinvent data. This method was utilized for $\mathrm{H}_{12} \mathrm{MDI}$, polycarbonate hexanediol, dimethylethanol amine, 1-methoxypropan-2-ol, DPGDME and PPG-diamine $\mathrm{D}$ 230. The chemicals used in the substitution reactions were aniline $\left(\mathrm{C}_{6} \mathrm{H}_{5} \mathrm{NH}_{2}\right)$, formaldehyde $\left(\mathrm{CH}_{2} \mathrm{O}\right)$, phosgene $\left(\mathrm{COCl}_{2}\right)$, 1,6-hexanediol $\left(\mathrm{C}_{6} \mathrm{H}_{14} \mathrm{O}_{2}\right)$, methanol $\left(\mathrm{CH}_{3} \mathrm{OH}\right)$, ethylene oxide $\left(\mathrm{C}_{2} \mathrm{H}_{4} \mathrm{O}\right)$, dimethyl amine $\left(\left(\mathrm{CH}_{3}\right)_{2} \mathrm{NH}\right)$, propylene oxide $\left(\mathrm{C}_{3} \mathrm{H}_{6} \mathrm{O}\right)$, propylene glycol $\left(\mathrm{C}_{3} \mathrm{H}_{8} \mathrm{O}_{2}\right)$, and ammonia $\left(\mathrm{NH}_{3}\right)$. The stoichiometric reactions governing their synthesis and their source are shown in Table 1.

For all three groups, the production of the chemicals was modeled with a system terminated process, also called result process. Every form of energy consumption, such as the powering of the stirring units or the heating during the manufacturing unit operations (UOs), was modeled with the same system terminated process called Electricity, high voltage, production mix [AT]. Condensed in it is information of the recorded shares of electricity technologies of the Austrian energy market of the year 2014. 
Table 1: Overview of the Life Cycle Inventory Data used for Modeling the Production of the Input Chemicals in the Background System. ${ }^{a}$

\begin{tabular}{|c|c|c|c|}
\hline group & chemical & process & dataset/source \\
\hline \multirow{5}{*}{ (1) ecoinvent } & NMP & NMP & $N$-methyl-2-pyrrolidone production [RER] \\
\hline & acetone & acetone & acetone production, liquid [RER] \\
\hline & deionized water & all four & water production, deionized, from tap water, at \\
\hline & Geionized water & dil IOUT & user $[\mathrm{CH}]$ \\
\hline & triethyl amine & NMP, acetone & triethyl amine production [RER] \\
\hline \multirow{4}{*}{$\begin{array}{l}\text { (2) substitutes } \\
\text { from ecoinvent }\end{array}$} & 1,6-hexanediol & NMP, acetone & 2,5-dimethyl-2,5-hexanediol \\
\hline & DMPA & all four & propionic acid \\
\hline & TMXDI & all four & toluene diisocyanate \\
\hline & triethylenetetramine & NMP, acetone & ethylenediamine \\
\hline \multirow{6}{*}{$\begin{array}{l}\text { (3) modeled from } \\
\text { literature }\end{array}$} & $\mathrm{H}_{12} \mathrm{MDI}$ & all four & $\mathrm{C}_{6} \mathrm{H}_{5} \mathrm{NH}_{2}+\mathrm{CH}_{2} \mathrm{O}+\mathrm{COCl}_{2}{ }^{26}$ \\
\hline & polycarbonate hexanediol & all four & $\mathrm{C}_{6} \mathrm{H}_{14} \mathrm{O}_{2}+\mathrm{CH}_{3} \mathrm{OH}+\mathrm{COCl}_{2}{ }^{1}$ \\
\hline & dimethylethanol amine & melt, flow & $\mathrm{C}_{2} \mathrm{H}_{4} \mathrm{O}+\left(\mathrm{CH}_{3}\right)_{2} \mathrm{NH}^{27}$ \\
\hline & 1-methoxypropan-2-ol & melt & $\mathrm{C}_{3} \mathrm{H}_{6} \mathrm{O}+\mathrm{CH}_{3} \mathrm{OH}^{28}$ \\
\hline & DPGDME & melt & ${ }_{2} \mathrm{C}_{3} \mathrm{H}_{6} \mathrm{O}+2 \mathrm{CH}_{3} \mathrm{OH}^{29}$ \\
\hline & PPG-diamine D 230 & melt, flow & $\mathrm{C}_{3} \mathrm{H}_{6} \mathrm{O}+\mathrm{C}_{3} \mathrm{H}_{8} \mathrm{O}_{2}+\mathrm{NH}_{3}{ }^{30}$ \\
\hline
\end{tabular}

a Additional information on the datasets used can be found in the Supporting Information.

Process Inventories. The data used in the inventory analysis were almost exclusively provided by Allnex Austria $\mathrm{GmbH}$. The industrial plant, where both the NMP and melt processes are being carried out, compiled the technical data. For these two processes, computer programs monitored reaction temperatures and process durations and delivered exact information of the energy flows. Consequently, average values of the last two years were taken into account. The stoichiometry of the reactions as well as log notes of the raw material consumption were processed to provide the remaining information governing the raw material usage that was still missing from the inventory. The data sets assembled were presumed to be very precise and accurate. The information for the acetone process was retrieved from literature as well as from synthesis at a smaller scale. The data of the acetone process are complete, consistent, and based on precise measurements. The extent to which the data of the flow process relies on actual laboratory measurements is limited. Details about the underlying assumptions of the data are given below.

In the following, the individual LCIs of the four compared processes are explicated. Figure 1 provides the process flow charts depicting the UOs performed in the corresponding reactors. For the NMP, acetone and melt process, respectively, the manufacturing unit consists of a main batch reactor where the prepolymer formation takes place and a dilution batch reactor for dispersion and chain extension. For the flow process on the other hand, only one reactor unit where all the reaction steps occur sequentially in a telescoped mode is employed.

It should be noted, that 1-methoxypropan-2-ol was utilized as reagent only in the melt process, but was employed as a cleaning agent for all four processes. It was therefore not implemented in Table 1 as input chemical for all processes, but grouped under the category "spent solvent" in the LCI (see Tables $\mathrm{S}_{1}-\mathrm{S}_{5}$ in the Supporting Information). Most of this solvent was modeled to be recycled; the remainder was disposed of.
NMP Process. Figure 1a provides the NMP process' flow chart. The NMP process required a total of $202.43 \mathrm{~kJ}$ per $\mathrm{kg}$ of finished PUD (Table 2). The total energy expenditure stems from the heating processes $(160.67 \mathrm{~kJ} / \mathrm{kg})$ and the operation of the stirring unit $(41.76 \mathrm{~kJ} / \mathrm{kg})$. For the calculation, the agitator's power output and the specific heat capacities $C_{p}$, as well as the mass of the mixture and the temperature difference by which the mixture was heated, was used. The UO of product completion comprised the charging of the mixture of water and chemicals utilized during dispersion and chain extension into the dilution reactor and its heating. This approach facilitated life cycling modelling in the Umberto LCA+ software, and importantly, did not alter results. The same methodology was applied for the melt process and was slightly varied for the acetone process.

Acetone Process. Unlike during the melt and NMP processes, distillation must be carried out before the product completion UO takes place (Figure 1a). Table $\mathrm{S}_{3}$ in the Supporting Information provides information regarding the modeled material inputs of the acetone process. Notably, the most decisive difference to the NMP process, apart from small deviations in the quantities of the chemicals employed, is the replacement of toxic NMP by acetone as solvent. Furthermore, acetone contributes to almost $1 / 3$ of the input mass flow, which needs to be removed from the dispersion again later via distillation. This gives rise to an issue concerning the capacity utilization rate of the reactors employed in this production method. Therefore, the amount of the finished PUD output produced per cycle is considerably diminished compared to the alternative production procedures.

In total, $786.51 \mathrm{~kJ} / \mathrm{kg}$ of energy is required during the UOs, of which $725.81 \mathrm{~kJ} / \mathrm{kg}$ are expended in the heating process and $60.70 \mathrm{~kJ} / \mathrm{kg}$ in the stirring process (Table 2). In contrast to the NMP process, the energy expenditure of the dilution reactor was assigned to the UO distillation and not product 
a) NMP and Acetone Process

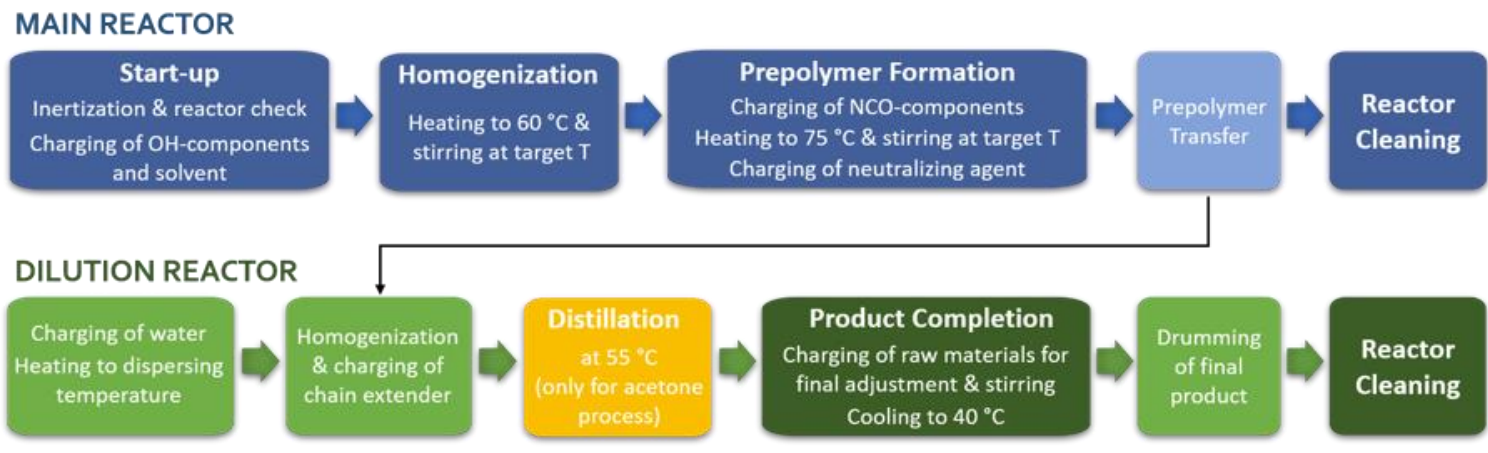

b) Melt Process

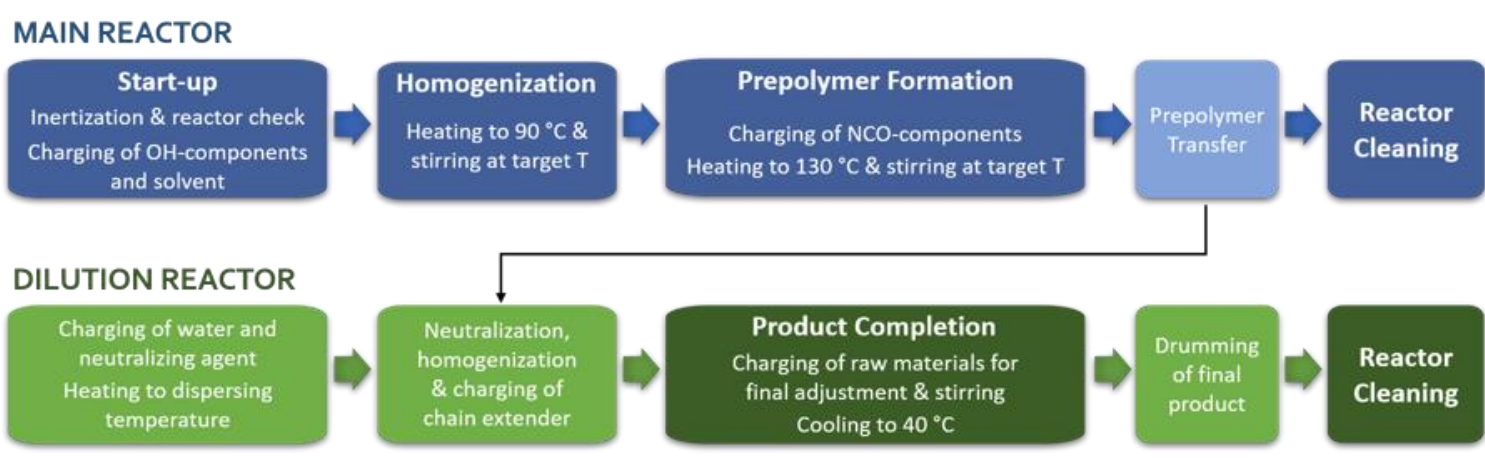

c) Flow Process

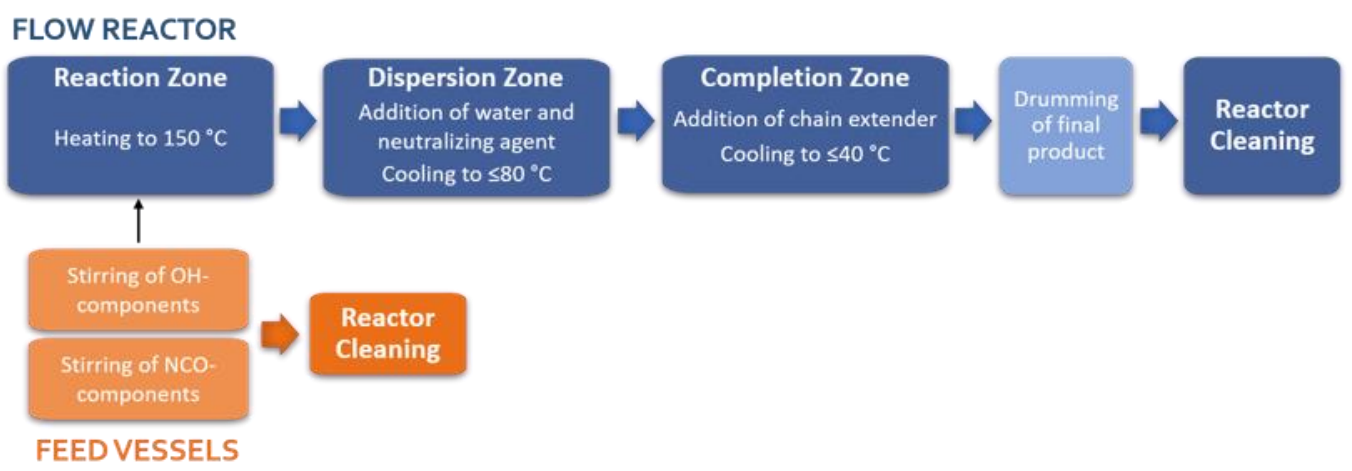

Figure 1. Process flow charts for the four compared PUD processes.

completion (see Table 2 and Table $S_{7}$ in the Supporting Information), since both dispersion and chain extension take place prior to distillation (see Figure 1a).

Melt Process. Apart from the fact that a higher reaction temperature of $130{ }^{\circ} \mathrm{C}$ (vs $75^{\circ} \mathrm{C}$ ) prevails, the flow chart of the melt process (Figure $\mathrm{ib}$ ) essentially resembles that of the NMP process. The melt process' inventory comprises the following new chemicals: Dimethylethanol amine, 1methoxypropan-2-ol, DPGDME and PPG-diamine D 230, which were modeled by the reactions displayed in Table 1. In contrast to the two processes described above, no organic solvent was utilized. The total energy expenditure of $191.67 \mathrm{~kJ} / \mathrm{kg}$ is divided between the heating process $(154.851$ $\mathrm{kJ} / \mathrm{kg}$ ) and the stirring unit $(36.82 \mathrm{~kJ} / \mathrm{kg})$.
Flow Process. When examining the flow process' flow chart, the deviation from the other methods becomes apparent: As can be seen from Figure 1c, it employs a single reactor unit, in which the process cycle is divided into various "zones". The separate dilution reactor is no longer necessary, as dispersion and product completion (chain extension) both take place within the flow reactor sequence. Instead, two feed vessels that continuously stir the raw material mixtures and from which the raw materials are pumped into the reactor were introduced. One feed consists of the diol components and the other comprises the diisocyanates. In terms of raw materials used, the flow process requires the same main components as the melt process (see Table $\mathrm{S}_{5}$ in the Supporting Information). In the flow process, the UOs take place without changing the prevailing conditions, hence, the energy expended was 
Table 2. Overview of the Energy Expenditure $(\mathrm{kJ} / \mathrm{kg})$ by Unit Operation of the PUD Manufacturing Phase.

\begin{tabular}{|c|c|c|c|c|c|c|c|c|c|c|c|c|}
\hline \multirow[b]{2}{*}{ unit operation } & \multicolumn{3}{|c|}{ NMP Process } & \multicolumn{3}{|c|}{ Acetone Process } & \multicolumn{3}{|c|}{ Melt Process } & \multicolumn{3}{|c|}{ Flow Process } \\
\hline & heating & stirring & total & heating & stirring & total & heating & stirring & total & heating & stirring & total \\
\hline start up & - & 0.53 & 0.53 & - & 0.66 & 0.66 & - & 0.53 & 0.52 & & & \\
\hline homogenization & - & 3.27 & 3.27 & - & 4.10 & 4.10 & 8.69 & 1.97 & 10.66 & & & \\
\hline prepolymer formation & - & 23.31 & $23 \cdot 31$ & - & 29.22 & 29.22 & - & 6.61 & 6.61 & & & \\
\hline distillation & - & - & - & 610.63 & 16.92 & $627 \cdot 55$ & - & - & - & & & \\
\hline product completion $^{\mathrm{a}}$ & 68.76 & $7 \cdot 30$ & 76.06 & - & 0.59 & 0,59 & 53.68 & 20.31 & 73.99 & & & \\
\hline reactor cleaning & 91.91 & $7 \cdot 35$ & 99.26 & 115.18 & 9.21 & $124 \cdot 39$ & 92.48 & $7 \cdot 40$ & 99.88 & & & \\
\hline feed vessels & & & & & & & & & & - & 10.05 & 10.05 \\
\hline flow reactor & & & & & & & & & & 8.58 & - & 8.58 \\
\hline reactor cleaning & & & & & & & & & & 8.65 & 0.69 & $9 \cdot 34$ \\
\hline total & 169.67 & 41.76 & 202.43 & 725.81 & 60.70 & 786.51 & 154.85 & 36.82 & 191.67 & 17.23 & 10.74 & $\mathbf{2 7 \cdot 9 7}$ \\
\hline
\end{tabular}

${ }^{\text {a }}$ Includes charging of water and prepolymer transfer to the dilution reactor as well as its heating for the NMP and melt processes.

Table 3. Durations and Temperatures used in Modeling the Manufacturing Phase of the Four PUD Processes.

\begin{tabular}{|c|c|c|c|c|c|c|c|c|}
\hline \multirow[b]{2}{*}{ unit operation } & \multicolumn{2}{|c|}{ NMP Process } & \multicolumn{2}{|c|}{ Acetone Process } & \multicolumn{2}{|c|}{ Melt Process } & \multicolumn{2}{|c|}{ Flow Process } \\
\hline & $\min$ & ${ }^{\circ} \mathrm{C}$ & $\min$ & ${ }^{\circ} \mathrm{C}$ & $\min$ & ${ }^{\circ} \mathrm{C}$ & $\min$ & ${ }^{\circ} \mathrm{C}$ \\
\hline start-up & 90 & 60 & 90 & 60 & 90 & 66 & & \\
\hline homogenization & 100 & 60 & 100 & 60 & 60 & 90 & & \\
\hline prepolymer formation & 890 & 75 & 890 & 75 & 250 & 130 & & \\
\hline prepolymer transfer & 90 & - & 30 & - & 30 & - & & \\
\hline distillation & - & - & 600 & 55 & - & - & & \\
\hline product completion & 150 & 40 & 30 & 40 & 300 & 35 & & \\
\hline reaction zone & & & & & & & 30.0 & 150 \\
\hline dispersion zone & & & & & & & 0.5 & $\leq 80$ \\
\hline completion zone & & & & & & & 0.5 & $\leq 40$ \\
\hline total duration & 1320 & & 1740 & & 730 & & 31.0 & \\
\hline
\end{tabular}

differentiated as illustrated in Table 2. The overall energy expenditure of the flow process amounts to only 27.97 $\mathrm{kJ} / \mathrm{kg}$, whereby $36 \%(10.05 \mathrm{~kJ} / \mathrm{kg})$ of the total energy consumption are accounted for the stirring units inside the two feed vessels (Table 2). Only the feed stream of the $\mathrm{OH}$ functionalized building blocks (DMPA, polycarbonate hexanediol) must be preheated to $90^{\circ} \mathrm{C}$.

All individual "zones" were subsumed under the name "flow reactor". During the prepolymer formation reaction, the exothermic reaction leads to no further energy expenditure, as per usual. In contrast to the other three processes, where the reactors are cleaned after every production cycle completion, the flow reactor implements this step only after every tenth production cycle.

Comparison of Process Conduct. In Table 3 the durations and temperatures of the four PUD processes are shown. It has to be noted that the preheating of the reactor before the chemicals are pumped into the vessels and reactor cooling after they are emptied are included in the UOs, which greatly increased the values of the duration of the UOs compared to only considering the reaction time. For instance, in the melt process the prepolymer formation occurring in the main reactor needs $2 \mathrm{~h}$, whereas the UO "prepolymer formation" took $4.2 \mathrm{~h}$ in total. The same applies for the acetone process: The entire UO of distillation requires $10 \mathrm{~h}$, whereas the full process temperature is sustained for only $6 \mathrm{~h}$. Importantly, the reactor preheating and post-cooling phases can be generally omitted in the flow process. Due to the continuous succession of production cycles, the temperatures can be permanently sustained at the desired levels. The higher process temperature in the flow process leads to a drastic decrease of the overall processing time (see Table 3). Both the dispersion, which has 
already been performed continuously in small scale laboratory experiments, and the product completion are expected to be carried out within less than $1 \mathrm{~min}$. This extremely rapid UO performance becomes noticeable in the reduced energy requirements relative to the functional unit of $1 \mathrm{~kg}$ of finished PUD. From an economic point of view, the possibility of an enhanced production rate represents an appealing advantage for the practical adoption of the flow process on manufacturing scale.

In summary, the flow process requires the least time (31 $\mathrm{min})$, followed by the melt (730 min), the NMP (1320 min) and the acetone process (1740 min). The shorter processing times of the flow and melt process can be mainly attributed to the higher temperatures (up to $75^{\circ} \mathrm{C}$ ) employed in the prepolymer formation reaction. The NMP and melt process exhibit a comparable energy expenditure of around $200 \mathrm{~kJ} / \mathrm{kg}$ of finished product. Owed to the additional distillation step, the acetone process' energy demand far surpasses both with a value of $786 \mathrm{~kJ} / \mathrm{kg}$. On the other hand, the energy required for the flow process was estimated to be only about $28 \mathrm{~kJ} / \mathrm{kg}$.

Life Cycle Impact Assessment (LCIA). Figure 2 provides a comparison of the processes' environmental impacts relative to each impact category. As can be seen, the flow process exhibits the lowest impacts across all six CML 2001 baseline indicators. The melt process ranks second in four of the six impact categories and third in the categories EU and HT potential. The NMP process exhibits the highest impacts in all categories.

The superior environmental performance of the flow process can be attributed foremost to the less impactful upstream chemical supply chain (see Figure 3). Second, the energy expenditure throughout the manufacturing UOs was reduced by $85-96 \%$ compared to the other processes (see Table 2). For the categories of CC and HT, the categories with the most pronounced results, the synthesis of 2,5dimethyl-2,5-hexanediol and aniline (modeled substrate for the $\mathrm{H}_{12}$ MDI synthesis, see Table 1 ) have the largest impact. It needs to be pointed out that the impact for the production of 2,5-dimethyl-2,5-hexanediol equates mainly to the production of polycarbonate hexanediol, where it serves as substitute for 1,6-hexanediol that is used as modeled reagent for polycarbonate hexanediol synthesis (see Table 1), The same is true for the other PUD processes (vide infra).

The second ranking melt process resembles the flow process most closely, apart from longer reaction times and a larger number of UOs throughout the manufacturing phase. The largest contributions to the final result were related to the production processes of 2,5-dimethyl-2,5-hexanediol, aniline, and propylene oxide. The latter, together with the synthesis of propylene glycol, were responsible for a higher impact in the HT potential compared to the acetone process. Propylene oxide and propylene glycol were used for the modeling of 1-methoxypropan-2-ol, DPGDME, and PPG-diamine D 230 (see Table 1).
The acetone process ranks third, because of higher impacts than the melt process in four impact categories. The comparably high energy consumption, which is related to the additional distillation UO, increases the negative impact, particularly in the CC potential. The UO of distillation required roughly three times the energy as the entire melt process in total $(610.63 \mathrm{vs} 191.67 \mathrm{~kJ} / \mathrm{kg}$, see Table 2$)$. However, the distillation only contributes an insignificant part of the acetone process' total impact, as the footprint of the raw material production by far exceeds that of the manufacturing process.

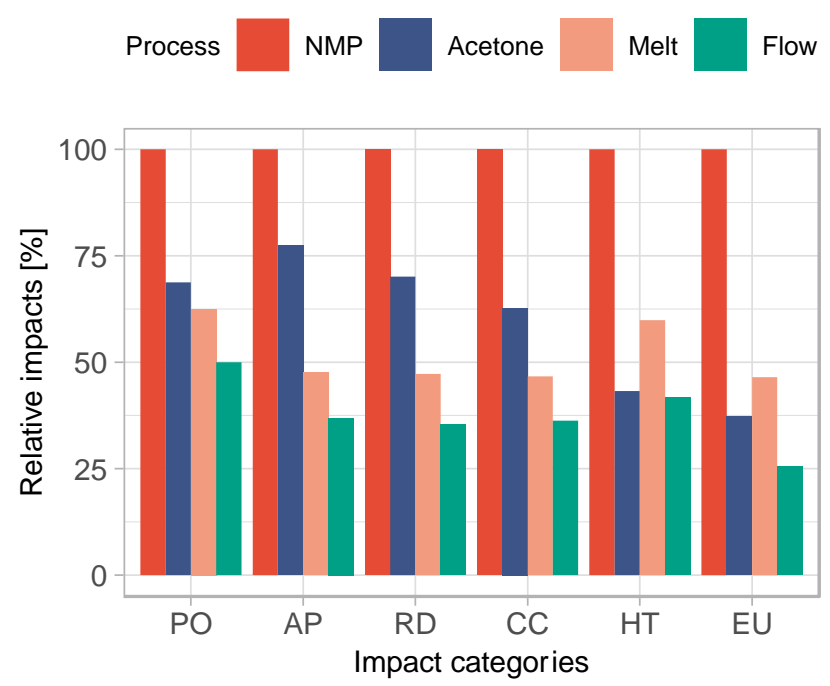

Figure 1. Relative environmental impact per PUD production process and CML 2001 baseline indicator. $\mathrm{PO}=$ Photochemical oxidation potential $\left[\mathrm{kg} \mathrm{C}_{2} \mathrm{H}_{4}\right.$-eq], $\mathrm{AP}=$ Acidification potential [ $\mathrm{kg} \mathrm{SO}_{2}$-eq], $\mathrm{RD}=$ Abiotic resource depletion potential [ $\mathrm{kg} \mathrm{Sb}$ eq], $\mathrm{CC}=$ Climate change as global warming potential -100 years $\left[\mathrm{kg} \mathrm{CO} \mathrm{CO}_{2}\right.$-eq], $\mathrm{HT}=$ Human toxicity potential [ $\mathrm{kg} 1,4^{-}$ DCB-eq], EU = Eutrophication potential [ $\mathrm{kg} \mathrm{NO}_{\mathrm{x}}$-eq].

For the NMP process, it must be pointed out that the employment of the toxic solvent proved to have a significant effect on the overall environmental impact, most notably in that of EU, HT and RD. For the EU, CC and HT impact categories, even the production of NMP alone had a larger impact than the overall impact of the other PUD processes (see Figure 3). When averaging over all six impact categories, the NMP synthesis process was approximately twice as impactful as that of 2,5-dimethyl-2,5-hexanediol production, the second-most impactful UO. A positive aspect to be noted about the NMP process is that it produces fewer harmful emissions during the manufacturing operations compared to the acetone process, however, it was still outperformed by the melt and flow processes.

In summary, the manufacturing UOs carried out at the PUD producer were shown to be considerably less impactful than the impacts generated in the upstream supply chain of the input chemicals. The manufacturing UOs only 


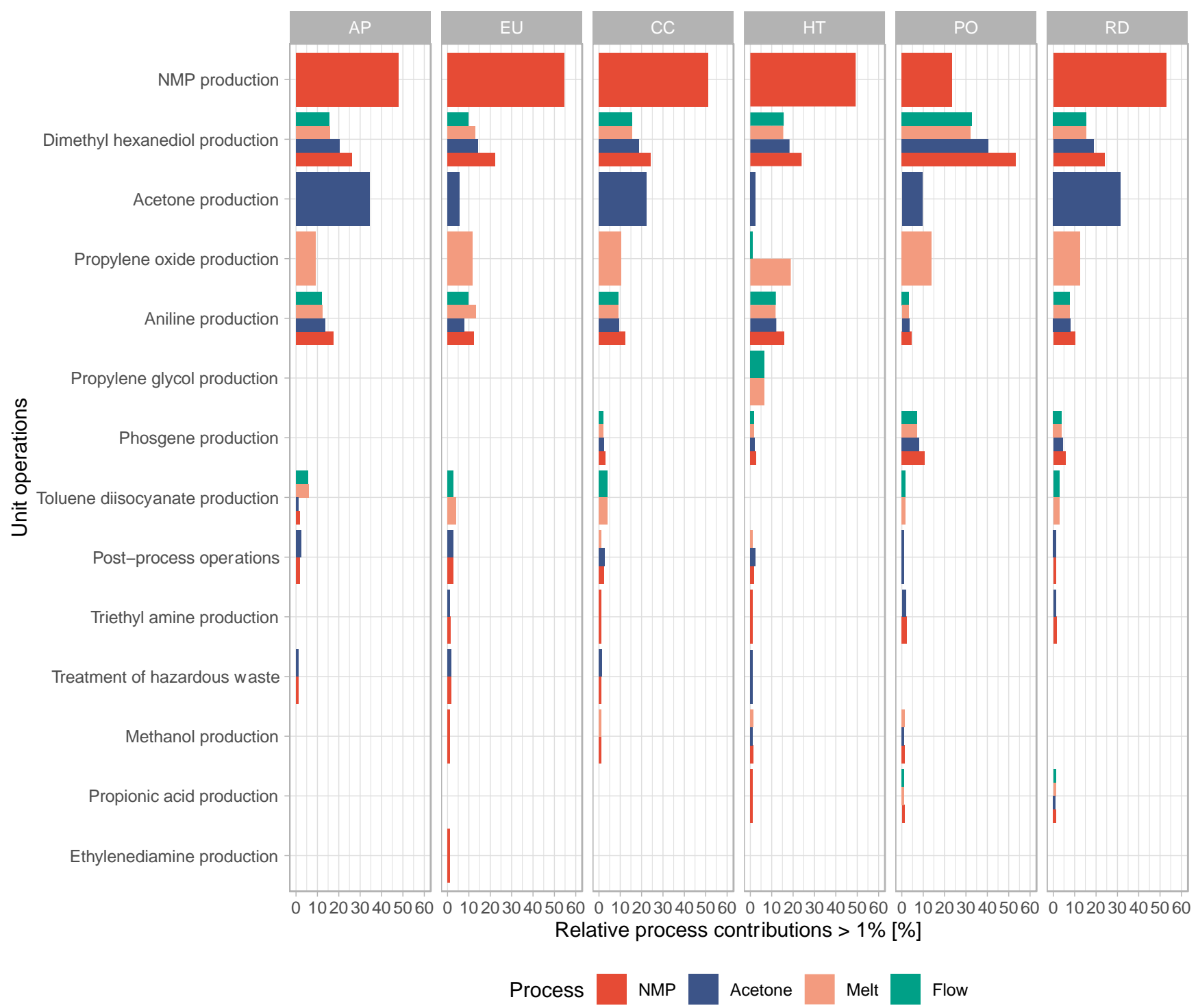

Figure 3. Relative process contributions $>1 \%$ of the upstream UOs per PUD production process and CML 2001 baseline indicator. The relative process contributions for all UOs is displayed in Figure S26.

accounted for 2.08-6.04\% of the overall environmental impacts (see Figure $\mathrm{S}_{25}$ in the Supporting Information). Of these manufacturing UOs, the post-processing that accounts for the cleaning of the reactors and the disposal of the filters has the highest impact in the manufacturing phase. Overall, the most impactful UOs were related to the provision of NMP, acetone, 2,5-dimethyl-2,5-hexanediol, aniline, propylene oxide and propylene glycol.

Limitations. A limitation of this study is that the energy expenditure in connection with the cooling system could not be determined exactly but instead was approximated. Furthermore, the use of generic data for modeling the background system, while common practice, serves as a source of uncertainty, as the generic data may not reflect the current state of technology fully. An additional source of scenario uncertainty arises from the assumption of scal- ing up the flow process from laboratory to industrial production scale. The class of parameter uncertainty played a role during the assessment of certain values, such as the specific heat capacities of the mixtures inside the reactors. However, since these issues are the same for all four production methods, it can be rightfully assumed that the overall comparison was not distorted by this influence. Moreover, when employing the same impact categories proposed by methodologies other than CML 2001, results may differ slightly. These variations among different impact assessment methods are a consequence of intrinsic differences of the characterization models. ${ }^{31}$ Finally, another limitation refers to the lack of an uncertainty analysis of the results, for instance via a Monte Carlo simulation. However, it can be expected that the overall predominance of the flow process would not change when considering uncertainty ranges. 


\section{CONCLUSION}

In this study, four different production processes of waterborne polyurethane dispersions were compared regarding their environmental impacts from cradle-to-gate. Using the LCA methodology in line with the ISO 14040-44 standards, the NMP process, the acetone process, the melt process, and a conceptualized flow process were compared. The data on the PUD manufacturing processes, the foreground system, was provided by the Austrian PUD producer Allnex Austria GmbH. The continuous flow process was in part modeled as it is currently in the design stage. Data on the impacts associated with the production of the input chemicals (background system), were derived from the ecoinvent database and scientific literature. The environmental impacts were assessed using six CML 2001 baseline indicators.

The LCA revealed that the flow process exhibits a superior environmental performance in all six impact categories when compared to the three established process. The melt process ranks second, as it exhibits lower impacts than the third-ranking acetone process in four out of six impact categories. Trailing far behind was the NMP process. The production of its toxic solvent entailed severe adverse environmental effects.

The largest portion of the overall environmental impacts can be related to the production of 2,5-dimethly-2,5hexanediol, aniline, acetone, NMP, and propylene oxide. Moreover, it was observed that the majority of the processes' environmental impacts are caused in the production of the input chemicals. The PUD manufacturing, including the prepolymer preformation reaction and the successive UOs for product completion, accounted only for 2.08-6 \% of the total environmental impacts. This held true for all process conducts.

Further research may focus on expanding the LCA's scope to also include the PUD's use and end-of-life phases. Furthermore, the more specific investigations focusing on the environmental impacts associated with the synthesis of the chemicals used during PUD production could be carried out. Possible measures, such as identifying less impactful synthesis routes or altering the raw material inputs in favor of renewable materials could be contemplated.

\section{ASSOCIATED CONTENT}

Supporting Information. Additional LCA information: LCIs, energy inputs and LCA results of individual processes. This material is available free of charge via the Internet at http://pubs.acs.org.

\section{AUTHOR INFORMATION}

\section{Corresponding Author}

* rupert.baumgartner@uni-graz.at, oliver.kappe@uni-graz.at.

\section{Notes}

The authors declare no competing financial interest.

\section{ACKNOWLEDGMENT}

The CC Flow Project (Austrian Research Promotion Agency FFG No. 862766) is funded through the Austrian COMET Program by the Austrian Federal Ministry of Transport, Innovation and Technology (BMVIT), the Austrian Federal Ministry of Science, Research and Economy (BMWFW), and by the State of Styria (Styrian Funding Agency SFG). The funding of the Christian Doppler Laboratory for Sustainable Product Management by the Austrian Federal Ministry for Digital and Economic Affairs, the National Foundation for Research, Technology and Development, and the Christian Doppler Research Association, is gratefully acknowledged.

\section{ABBREVIATIONS}

TMXDI, tetramethylxylene diisocyanate; $\mathrm{H}_{12} \mathrm{MDI}$, 4,4'-dicyclohexylmethane diisocyanate; DPGDME, dipropylene glycol dimethyl ether.

\section{REFERENCES}

(1) Meier-Westhues, U.; Danielmeier, K.; Kruppa, P.; Squiller, E. P. Polyurethanes: Coatings, Adhesives and Sealants, 2nd Editio.; Vincentz Network, Hanover, 2019.

(2) Tennebroek, R.; van der Hoeven-van Casteren, I.; Swaans, R.; van der Slot, S.; Stals, P. J. M.; Tuijtelaars, B.; Koning, C. Water-Based Polyurethane Dispersions. Polym. Int. 2019, 68.

(3) Szycher, M. Szycher's Handbook of Polyurethanes, 2nd editio.; CRC Press, Taylor \& Francis Group: Boca Raton, FL, 2013.

(4) Dieterich, D. Aqueous Emulsions, Dispersions and Solutions of Polyurethanes; Synthesis and Properties. Progress in Organic Coatings. Elsevier November 1981, pp 281-340.

(5) In the European Union, the VOC Solvents Emissions Directive is the main policy instrument for the reduction of industrial emissions of VOCs: https://ec.europa.eu/environment/archives/air/stationary/s olvents/ (accessed February 24, 2021).

(6) NMP is classified as carcinogenic, mutagenic and toxic for reproduc-tion (CMR).

(7) Commission Regulation (EU) 2018/588 of 18 April 2018 amending Annex XVII to REACH regards NMP not be placed on the market as a substance on its own or in mixtures in a concentration $\geq 0.3 \%$ after 9 May 2020 .

(8) Fernandes, I. P.; Costa, M. R. P. F. N.; Ferreira, M. J.; Barreiro, M. F. Water-Based Poly(Urethane-Urea) Dispersions Meeting the European Union Legislation. Polimery 2015, 6o, 536-540.

(9) Plutschack, M. B.; Pieber, B.; Gilmore, K.; Seeberger, P. H. The Hitchhiker's Guide to Flow Chemistry. Chem. Rev. 2017, 117, 11796-11893.

(10) Hessel, V.; Kralisch, D.; Kockmann, N.; Noël, T.; Wang, Q. Novel Process Windows for Enabling, Accelerating, and Uplifting Flow Chemistry. ChemSusChem 2013, 6, 746-789.

(11) Hessel, V. Process Windows - Gate to Maximizing Process Intensification via Flow Chemistry. Chem. Eng. Technol. 2009, 32, 1655-1681.

(12) Dallinger, D.; Kappe, C. O. Why Flow Means Green Evaluating the Merits of Continuous Processing in the Context of Sustainability. Curr. Opin. Green Sustain. Chem. 2017, 7, 6-12.

(13) Rogers, L.; Jensen, K. F. Continuous Manufacturing-the Green Chemistry Promise? Green Chem. 2019, 21, 3481-3498.

(14) Vaccaro, L. Sustainable flow chemistry: methods and applications. Weinheim: Wiley-VCH; 2017.

(15) Gutmann, B.; Kappe, C. O. Forbidden Chemistries - Paths to a Sustainable Future Engaging Continuous Processing. J. 
Flow Chem. 2017, 7, 65-71.

(16)

Escribà-Gelonch, M.; Bricout, J.; Hessel, V. Circular Economy Metrics for the Photo-High-p,T Continuous Multistep Synthesis of Vitamin D3. ACS Sustain. Chem. Eng. 2021, 9, https://doi.org/10.1021/acssuschemeng.oco8330.

(17) Chandra, S.; Karak, N. Environmentally Friendly Polyurethane Dispersion Derived from Dimer Acid and Citric Acid. ACS Sustain. Chem. Eng. 2018, 6, 16412-16423.

(18) Zafar, F.; Ghosal, A.; Sharmin, E.; Chaturvedi, R.; Nishat, N. A Review on Cleaner Production of Polymeric and Nanocomposite Coatings Based on Waterborne Polyurethane Dispersions from Seed Oils. Prog. Org. Coatings 2019, 131, 259-275.

(19) Man, L.; Feng, Y.; Hu, Y.; Yuan, T.; Yang, Z. A Renewable and Multifunctional Eco-Friendly Coating from Novel Tung OilBased Cationic Waterborne Polyurethane Dispersions. J. Clean. Prod. 2019, 241, 118341.

(20) Gurunathan, T.; Arukula, R. High Performance Polyurethane Dispersion Synthesized from Plant Oil Renewable Resources: A Challenge in the Green Materials. Polym. Degrad. Stab. 2018, 150, 122-132.

(21) AL-Oqla, F. M.; El-Shekeil, Y. A. Investigating and Predicting the Performance Deteriorations and Trends of Polyurethane Bio-Composites for More Realistic Sustainable Design Possibilities. J. Clean. Prod. 2019, 222, 865-870.

(22) ISO. 14044: Environmental Management -- Life Cycle Assessment -- Requirements and Guidelines; ISO (International Organization for Standardization): Geneva, Switzerland, 2006.

(23) Wernet, G.; Bauer, C.; Steubing, B.; Reinhard, J.; MorenoRuiz, E.; Weidema, B. The Ecoinvent Database Version 3 (Part I): Overview and Methodology. Int. J. Life Cycle Assess. 2016, 21, 1218-1230.

(24) Steubing, B.; Wernet, G.; Reinhard, J.; Bauer, C.; MorenoRuiz, E. The Ecoinvent Database Version 3 (Part II): Analyzing LCA Results and Comparison to Version 2. Int. J. Life Cycle Assess. 2016, 21, 1269-1281.
Hischier, R.; Hellweg, S.; Capello, C.; Primas, A. Establishing Life Cycle Inventories of Chemicals Based on Differing Data Availability. Int. J. Life Cycle Assess. 2005, 10, 59-67.

(26) a) Yang, J.; Wu, Xu.; Li, Y.; Cui, C.; Zhao, D.; Liu, X.; Wu, J.; Liu, R. Composite catalyst for catalytic decomposition of amine salt, its preparation method and method for preparing methylenedianiline (MDA) and polymethylenedianiline (PMDA) by using the same. CN108176392A, 2018; b) Zhao, Z, Fan, L. Method for preparation of aliphatic amines by reducing aromatic amine compounds. CN108191671A, 2018; c) Xue, Y. Preparation method of organic isocy-anate compounds by high temperature gas phase one-step reaction. CN107353231A, 2017

(27) Pape, F.-F.; Melder, J.-P.; Krause, A.; Bou Chedid, R.; Rudloff, M. Process for preparing an N,N-dialkylethanolamine having high color stability. WO2012080409A1, 2012.

(28) Timofeeva, M. N.; Kurchenko, J. V.; Kalashnikova, G. O.; Panchenko, V. N.; Nikolaev, A. I.; Gil, A. A Layered Titanosilicate AM-4 as a Novel Catalyst for the Synthesis of 1-Methoxy-2-Propanole from Propylene Oxide and Methanol. Appl. Catal. A Gen. 2019, 587, 117240.

(29) Product Safety Assessment PROGLYDE DMM Glycol Diether (Dipropylene Glycol Dimethyl Ether) from msdssearch.dow.com/PublishedLiteratureDOW-

COM/dh_096d/o901b8038096dbbb.pdf?filepath=productsafety/pdfs/noreg/233-00413.pdf\&fromPage=GetDoc (last accessed February 3, 2020).

(30) a) Jing, $X$. Method for synthesizing low unsaturation aromatic polyether polyol. CN110343239A, 2019; b) Zhao, S.; Jin, Y.; Yu, J.; Song, M.; Xiang, S. Supported catalyst, polyetheramine and preparation method thereof. CN110551278A, 2019.

(31) Bueno, C.; Hauschild, M. Z.; Rossignolo, J. A.; Ometto, A. R.; Mendes, N. C. Sensitivity Analysis of the Use of Life Cycle Impact Assessment Methods: A Case Study on Building Materials. J. Clean. Prod. 2016, 112, 2208-2220. 